\title{
Possible relation between consumption of different food groups and depression
}

\author{
G. Grases ${ }^{1}$, M. A. Colom², P. Sanchis ${ }^{3}$ and F. Grases ${ }^{3 *}$ (D)
}

\begin{abstract}
Background: Diverse studies have investigated the relationship between diet and depression. In fact some crosssectional studies suggested that a healthy diet reduced the risk for depression. The main objective of this study was to assess the relationship of consumption of different food groups with depression. The food groups were selected based on their content of substances that were precursors to neurotransmitters (tryptophan or inositol) or their effect on oxidative stress.

Methods: This observational retrospective study compared the diets of individuals who were with depressive symptoms (Beck Depression Inventory Questionnaire $[\mathrm{BDI}] \geq 10 ; 53$ women, 23 men, age 38+/-11) and with no depressive levels (BDI < 10; 33 women, 23 men, age 41+/-13). Dietary data were collected from a questionnaire that asked about consumption of legumes, nuts, whole-grain foods, fruits and vegetables, chocolate, and sweet foods and refined sugars.
\end{abstract}

Results: Depressed individuals consumed significantly lower amounts of legumes, fruits, and vegetables, but higher amounts of sweets and refined sugars ( $p<0.05$ for all comparisons). After statistical adjustment for age and sex, the consumption of no legumes (adjusted odds ratio $[\mathrm{aOR}]=2.60,95 \%$ confidence interval $[\mathrm{Cl}]=1.19-5.67$ ), low consumption of fruits and vegetables $(\mathrm{aOR}=2.69,95 \% \mathrm{Cl}=1.18-6.13)$, and high consumption of sweet foods and refined sugars ( $\mathrm{aOR}=1.91,95 \% \mathrm{Cl}=1.23-2.99)$ were significantly associated with depression. The two groups had no significant differences in the consumption of chocolate.

Discussion: The results indicate significant relationships of the consumption of certain foods with depression, although the study design precludes any conclusions regarding causality. Further studies are necessary to determine the causal relationships of the consumption of specific foods with depression, and of depression with the consumption of specific foods.

Conclusion: In spite of the limitations, we find that individuals without depression consumed more legumes, fruits, and vegetables, but fewer sweets and pastries than those with depression.

Keywords: Food, Depression, Precursors to neurotransmitters, Oxidative stress

\section{Background}

The data on prevalence of depression in Spain varied from $1.12 \%$ in preschool children, $8.56 \%$ in the general population and up to $55.6 \%$ in university students [1]. There are significant positive associations of depression with physical and other mental illnesses, the use of recreational drugs, and suicidal behaviors. Thus, depression is a major public health problem, and multi-disciplinary

\footnotetext{
* Correspondence: fgrases@uib.es

${ }^{3}$ University Institute of Health Sciences Research (IUNICS- IdisBa), University of Balearic Islands, Carretera Valldemossa Km 7,5, 07122 Palma de Mallorca, Spain

Full list of author information is available at the end of the article
}

study of depression is necessary to develop methods that reduce the symptoms and prevent its devastating effects.

Several studies have investigated the relationship between diet and depression. In particular, some cross-sectional studies suggested that a healthy diet reduced the risk for depression [2, 3]. Although there are fewer prospective studies, some prospective studies also reported a healthy diet reduced the risk of depression $[4,5]$. However, some other studies found no association between diet and depression [6].

Additional studies reported an association between oxidative stress and depression [7-9]. However, it remains

(C) The Author(s). 2019 Open Access This article is distributed under the terms of the Creative Commons Attribution 4.0 International License (http://creativecommons.org/licenses/by/4.0/), which permits unrestricted use, distribution, and 
unknown whether oxidative stress is a consequence of an unhealthy diet, of depression itself, or of both of these. Thus, recent studies proposed that depression can be treated by antioxidants [10]. In particular, a randomized placebo-controlled trial found that $\mathrm{N}$-acetyl-cysteine significantly reduced depression [10].

It should be noted that a healthy diet provides significant antioxidants that can reduce oxidative stress. Moreover, a healthy diet provides a source of tryptophan and inositol, which could be important for the synthesis of neurotransmitters [11], and function as secondary messengers in numerous signal transduction pathways [12]. Legumes are important sources of tryptophan, magnesium, and inositol hexaphosphate, also known as phytate (which is partly transformed into inositol in the intestine) [13]. On the other hand, some dietary components, such as refined sugars, can induce oxidative stress and appear to increase the risk of depressive behaviors [14-16].

There is also evidence that high adherence to the Mediterranean Diet (which has high amounts of fruits, vegetables, whole-grains, legumes, and nuts) is associated with a lower risk of depressive symptoms, particularly in men [17].

In the present retrospective observational study (from 2013 to 2017), we examined the relationship of consumption of different food groups (mainly containing antioxidants, tryptophan, inositol, refined sugars) with depression. Our hypothesis was that depression could be associated to the consumption of certain food groups.

\section{Methods}

This was an observational retrospective study of individuals admitted to the Psychology and Neurology Center (CLONUS, Mallorca, Spain) from 2013 to 2017. All individuals responded to a depression questionnaire and a simple dietary questionnaire. We examined the records of 56 individuals with no depressive levels (33 women and 23 men) and 76 individuals with depressive symptoms (53 women and 23 men). The mean $( \pm$ SD) age was $41.1( \pm 12.9)$ years in the non-depressed group and 38.7 $( \pm 11.0)$ years in the depression group. The two groups had no significant differences in sex or age.

These individuals were recruited by CLONUS among patients and volunteers that accomplished the following inclusion and exclusion criteria.

(1) Patients with severe mental health disorders (e.g., schizophrenia, major depression, bipolar disorder, and obsessive-compulsive disorder) were excluded. Only patients with a diagnostic of anxiety, depressive disorders, marital conflicts, or behavioral problems were included.

(2) Participants with eating disorders were excluded.
(3) Participants consuming antioxidant supplements or omega-3 PUFAs were excluded.

(4) Participants with severe health problems (e.g., cancer, serious cardiopathy) that need chronic pharmacologic treatment were excluded.

(5) Participants with addiction to alcohol or drugs were excluded.

All participants were Caucasian and belonging to median-high social status (they were from medium-high income households).

\section{Dietary questionnaire}

The data on diet were extracted from a non-validated broad questionnaire, which collected information on the consumption of different food groups (Additional file 1). In particular, this questionnaire collected information regarding the consumption of the following food groups: legumes, nuts, whole-grain foods, fruits and vegetables, chocolate, sweet foods and refined sugars. For each group, no consumption was considered as "no servings per week", low consumption as " 1 or 2 servings per week", and high consumption as " 3 or more servings per week". Servings per week were defined considering the consumptions considered as adequate in the Mediterranean diet [18]. The questionnaire was always personally passed by the same trained person.

\section{Depression questionnaire}

The validated Beck Depression Inventory (BDI) questionnaire was used to assess depression. Individuals with BDI scores below 10.00 were considered non-depressed, and those with scores of 10.00 or more as depressed [19].

\section{Statistical analyses}

Each value is expressed as mean $( \pm S D)$ or frequency (percentage). Patients were divided into a group with no depressive levels $(\mathrm{BDI}<10)$ and a group with depressive symptoms (BDI $\geq 10)$. The groups were compared using an independent samples Student's t-test for continuous variables, and a chi-square test for categorical variables. Estimated effect sizes were calculated using Cramer's V as a magnitude of association between depression and high, low or no consumption of the food groups.

Binary logistic regression was used to calculate the crude odds ratio (OR) and the OR adjusted for age and sex (aOR) for the relationship of consumption of each selected item with depression (dependent variable). A 2 -tailed $p$-value less than 0.05 was considered statistically significant. Statistical analyses were performed using SPSS 23.0 (SPSS Inc., Chicago, Illinois). 


\section{Results}

Table 1 shows the consumption of each of the different food groups by the individuals with no depressive levels and with depressive symptoms. There were significant differences in the consumption of legumes, fruits and vegetables, and sweets and refined sugars. More specifically, significantly greater percentages of depressed individuals consumed no legumes $(46.1 \%$ vs. $23.3 \%, p<0.05)$ and a significantly lower percentage of depressed individuals consumed 3 or more servings of fruits and vegetables per week $(57.9 \%$ vs. $80.4 \%, p<0.01)$. However, a higher percentage of depressed individuals consumed sweets and refined sugars $(36.8 \%$ vs. $16.1 \%, p<0.05)$. The two groups had no significant differences in the consumption of whole-grains, nuts and chocolate. As can be seen in Table 1, estimated effect sizes indicated a small-medium association (Cramer's $\mathrm{V}<0.3$ ) between depression and low consumption of legumes, fruits and vegetables; and high consumption of sweets and refined sugar.
We used binary logistic regression analysis (univariate and adjusted for age and sex) to identify the relationship of diet with depression. Univariate analysis indicated that consumption of no legumes, low consumption of fruits and vegetables ( $<3$ servings/weeks), and high consumption of sweets and refined sugars $(\geq 3$ servings weeks) were associated with depression $(p<0.05)$ (Fig. 1a). After adjusting for age and sex (Fig. 1b), consumption of no legumes $(\mathrm{aOR}=2.60,95 \%$ confidence interval $[\mathrm{CI}]=1.19$ 5.67), low consumption of fruits and vegetables $(\mathrm{aOR}=$ $2.69,95 \% \mathrm{CI}=1.18-6.13)$, and high consumption of sweets and refined sugars $(\mathrm{aOR}=1.91,95 \% \mathrm{CI}=1.23-2.99)$ were significantly associated with depression (Fig. 1b).

\section{Discussion}

A finding of our study is that individuals with no depressive levels consumed more legumes. This food group is rich in tryptophan, inositol, magnesium and other important nutrients, such as fibre, folate and omega-3 fatty acids. Previous studies established a beneficial effect

Table 1 Frequency (percentage) of food consumption in the groups with no depressive levels (Beck < 10) and with depressive symptoms (Beck $\geq 10)$ individuals

\begin{tabular}{|c|c|c|c|c|c|c|}
\hline \multirow{2}{*}{$\frac{\text { Diet category }}{\text { Legumes }}$} & \multicolumn{2}{|c|}{ No depression Beck < $10(N=56)$} & \multicolumn{2}{|c|}{ Depression Beck $\geq 10(N=76)$} & \multirow[t]{2}{*}{ Effect size Cramer's V Mean (95\% Cl) } & \multirow[t]{2}{*}{$p$} \\
\hline & & & & & & \\
\hline No consume & 13 & $(23.2 \%)$ & 35 & (46.1\%) & $0.24(0.07-0.40)$ & 0.026 \\
\hline Low consume & 34 & $(60.7 \%)$ & 33 & $(43.4 \%)$ & & \\
\hline High consume & 9 & $(16.1 \%)$ & 8 & $(10.5 \%)$ & & \\
\hline \multicolumn{7}{|l|}{ Nuts } \\
\hline No consume & 12 & $(21.4 \%)$ & 29 & (38.2\%) & $0.18(-0.02-0.38)$ & 0.115 \\
\hline Low consume & 21 & $(37.5 \%)$ & 24 & $(31.6 \%)$ & & \\
\hline High consume & 23 & $(41.1 \%)$ & 23 & $(30.3 \%)$ & & \\
\hline \multicolumn{7}{|l|}{ Cereals } \\
\hline No consume & 17 & $(30.4 \%)$ & 28 & $(36.8 \%)$ & $0.08(-0.22-0.38)$ & 0.641 \\
\hline Low consume & 10 & $(17.9 \%)$ & 10 & $(13.2 \%)$ & & \\
\hline High consume & 29 & $(51.8 \%)$ & 38 & $(50.0 \%)$ & & \\
\hline \multicolumn{7}{|c|}{ Fruits and vegetables } \\
\hline No consume & 8 & $(14.3 \%)$ & 10 & (13.2\%) & $0.30(0.09-0.51)$ & 0.003 \\
\hline Low consume & 3 & $(5.4 \%)$ & 22 & (28.9\%) & & \\
\hline High consume & 45 & $(80.4 \%)$ & 44 & (57.9\%) & & \\
\hline \multicolumn{7}{|l|}{ Sweets ans pastries } \\
\hline No consume & 25 & $(44.6 \%)$ & 32 & (42.1\%) & $0.26(0.08-0.44)$ & 0.013 \\
\hline Low consume & 22 & $(39.3 \%)$ & 16 & (21.1\%) & & \\
\hline High consume & 9 & $(16.1 \%)$ & 28 & $(36.8 \%)$ & & \\
\hline \multicolumn{7}{|l|}{ Chocolate } \\
\hline No consume & 23 & $(41.1 \%)$ & 32 & (42.1\%) & $0.14(-0.24-0.51)$ & 0.280 \\
\hline Low consume & 18 & $(32.1 \%)$ & 16 & (21.1\%) & & \\
\hline High consume & 15 & $(26.8 \%)$ & 28 & $(36.8 \%)$ & & \\
\hline
\end{tabular}




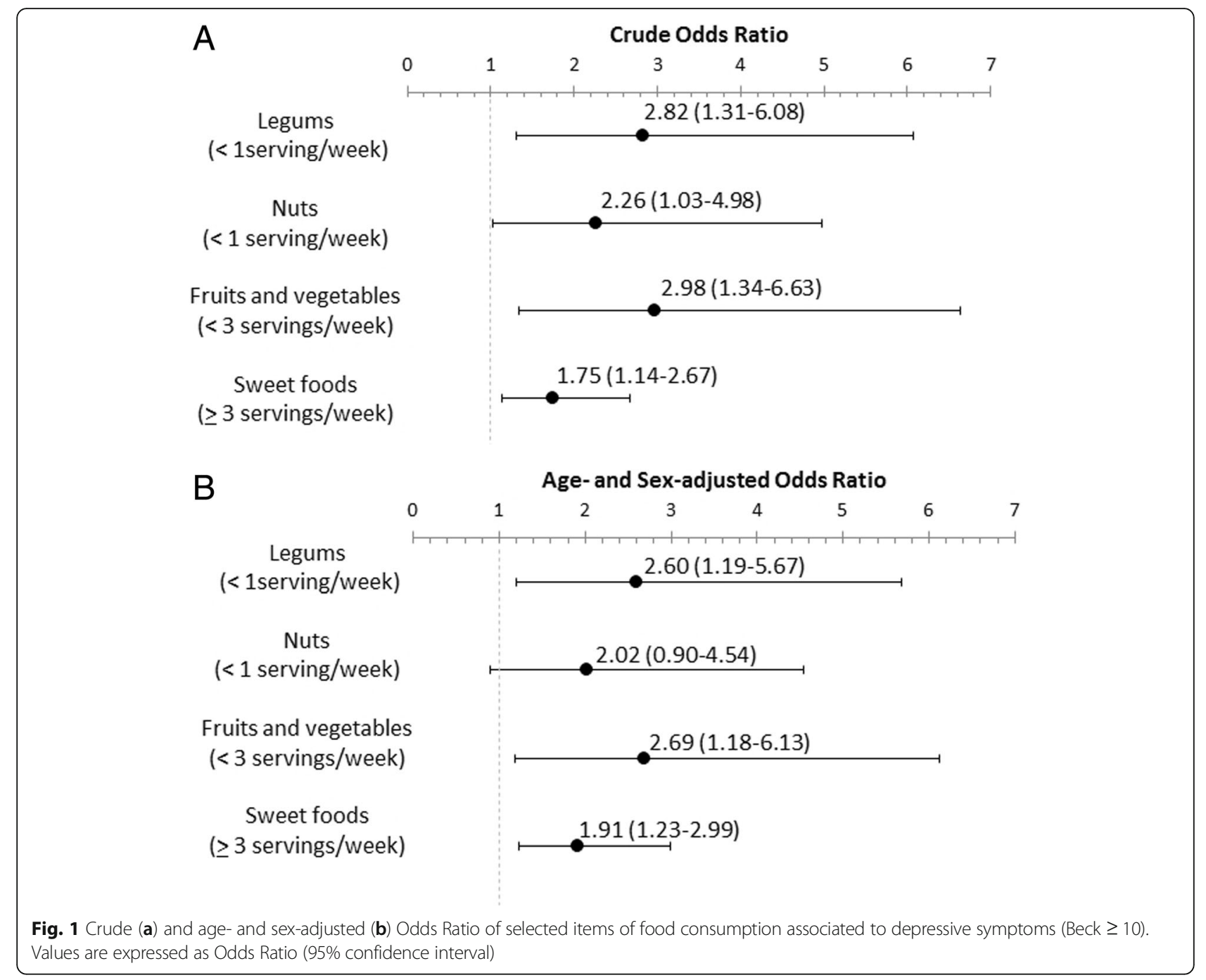

of consumption of tryptophan, inositol, and magnesium on the mental well-being of individuals. For example, a cross-sectional study demonstrated that higher tryptophan intake was independently associated with a lower prevalence of depression in young Japanese women [11]. Previous studies also reported lower consumption of fruits and vegetables in depressed individuals, and this is consistent with the presence of greater oxidative stress in depressed individuals [9, 20-22]. In addition, the higher consumption of sweet foods and refined sugars by depressed individuals may contribute to their increased oxidative stress. In fact, diets rich in sugars seem to induce depression [14-16]. Lipid peroxidation seems to play a role in diet-induced alterations related to behavioral disorders [14]. It is important to note that high oxidative stress can induce other pathologies, and a high level of reactive oxygen species (peroxides, superoxide, hydroxyl radical, singlet oxygen, alpha-oxygen, known as oxidative stress) is related to autoimmune responses [23, 24].
Thus, there is abundant evidence that consumption of certain foods is associated with depression and with a pathological state that leads to depression. However, further studies are necessary to determine the possible protective effect of different foods on the development of depression.

The main limitation of our study is the retrospective cross-sectional nature with a small sample, which precludes conclusions regarding the temporal nature of our findings and no solid conclusions can be established. Even though we found that the consumption of some food groups is associated to depression, we cannot confirm which one is the cause and which is the effect and also we cannot rule out a "third" explanation where there is no causal relationship between diet and depression. Another limitation is the use of a not-validated dietary food survey where the ingested amounts of each product are not specified. In addition, non-depressed individuals have been selected among patients who went to the Center of Psychology and Neurology, so they are 
people who, although not depressed, may suffer some kind of non-serious disease. Therefore, the group without depression is not, a group of totally healthy individuals. Also, the profession and social status have not been considered, although all the participants can be considered to belong to a medium-high social status. For all these reasons, prospective studies are needed to establish the time sequence in the relationship between them and clinically relevant findings.

\section{Conclusion}

In spite of these limitations, we observed significant differences in the diets of individuals with no depressive levels and with depressive symptoms. In particular, individuals without depression consumed more legumes, fruits, and vegetables, but fewer sweets and pastries than those with depressive symptoms.

\section{Additional file}

Additional file 1: Dietary Questionnaire used to obtain the information on the consumption of different food groups (Legumes, Nuts, Whole grain foods, Fruits and vegetables, Chocolate, Sweet foods and refined sugars). (DOC $45 \mathrm{~kb}$ )

\section{Abbreviations}

aOR: Adjusted odds ratio; BDI: Beck Depression Inventory Questionnaire; Cl: Confidence interval; DSM-5: Diagnostic and statistical manual; PUFAs: Polyunsaturated fatty acids; SPSS: Statistical package for social sciences

\section{Acknowledgements}

We give special thanks to all participants for their cooperation during data collection.

\section{Availability of data and materials}

The datasets used and analysed during the current study are available from the corresponding author on reasonable request.

\section{Authors' contributions}

GG, MAC and FG conceived the study and participated in study design. GG and FG drafted the manuscript. GG and PS participated in data analysis. All the authors read and approved the final manuscript.

\section{Ethics approval and consent to participate}

All procedures performed in studies involving human participants were in accordance with the ethical standards of the institutional and/ or national research committee and with the 1964 Helsinki declaration and its later amendments or comparable ethical standards.

Participants were informed about the purpose of the study, and they were assured that they answers would only be used anonymously for research purposes on a voluntary basis.

All participants aged 18 and above were given information about the study, and they were asked for they voluntary participation. A written informed consent was administered to each participant; all participants read and signed written consent forms before being enrolled in the study. The institutional review board of the Balearic Islands Community approved the study (number IB 1912/12 PI).

\section{Consent for publication}

Not applicable.

\section{Competing interests}

The authors declare that they have no competing interests.

\section{Publisher's Note}

Springer Nature remains neutral with regard to jurisdictional claims in published maps and institutional affiliations.

\section{Author details}

${ }^{1}$ Centro de Enseñanza Superior Alberta Jiménez (CESAG), 07013 Palma de Mallorca, Spain. ${ }^{2}$ Psycology and Neurology Center (CLONUS), 07014 Palma de Mallorca, Spain. ${ }^{3}$ University Institute of Health Sciences Research (IUNICSIdisBa), University of Balearic Islands, Carretera Valldemossa Km 7,5, 07122 Palma de Mallorca, Spain.

Received: 27 August 2018 Accepted: 25 February 2019

Published online: 06 March 2019

\section{References}

1. Cardila F, Martos A, Barragan AB, Perez-Fuentes MC, Molero MM, Gazquez JJ. Prevalence of depression in Spain: analysis of the last 15 years. Eur J Investiga. 2015;5(2):267-79. https://doi.org/10.1989/ejihpe.v5i2.118.

2. Rahe $\mathrm{C}$, Unrath $\mathrm{M}$, Berger $\mathrm{K}$. Dietary patterns and the risk of depression in adults: a systematic review of observational studies. Eur J Nutr. 2014:53:9971013. https://doi.org/10.1007/s00394-014-0652-9

3. Lai JS, Hiles S, Bisquerra A, Hure AJ, McEvoy M, Attia J. A systematic review and meta-analysis of dietary patterns and depression in communitydwelling adults. Am J Clin Nutr. 2014;99:181-97. https://doi.org/10.3945/ ajcn.113.069880

4. Dipnall JF, Pasco JA, Meyer D, Berk M, Williams $\sqcup$, Dodd S, Jacka FN. The association between dietary patterns, diabetes and depression. J Affect Disord. 2015;174:215-24. https://doi.org/10.1016/j.jad.2014.11.030.

5. Ruusumen A, Lehto SM, Mursu J, Tolmunen T, Toumainen TP, Kauhanen J, Voutilainen S. Dietary patterns are associated with the prevalence of elevated depressive symptons and the risk of getting a hospital discharge diagnosis of depression in middle-aged or older Finnish men. J Affect Disord. 2014;159:1.6. https://doi.org/10.1016/j.jad.2014.01.020.

6. Gougeon L, Payette H, Morais J, Gaudreau P, Shatenstein B, Gay-Donald K. Dietary patterns and incidence of depression in a cohort of communitydwelling older Canadians. J Nutr Health Aging. 2015;19:431-6. https://doi. org/10.1007/s12603-014-0562-9.

7. Maes M, Galecki P, Chang YS, Berk M. A review on the oxidative and nitrosative stress pathways in the major depression and their possible contribution to the (neuro) degenerative processes in that illness. Prog Neuro-Psychopharmacol Biol Psychiatry. 2011;35(3):676-92. https://doi.org/ 10.1016/.jpnpbp.2010.05.004

8. Rammal H, Bouayed J, Younos C, Soulimani R. The impact of high anxiety level on the oxidative status of mouse periphereal blood lymphocytes, granulocytyes and monocytes. Eur J Pharmacol. 2008;598(1-3):173-5. https://doi.org/10.1016/j.ejphar.2008.06.053.

9. Grases G, Colom MA, Fernandez RA, Costa-Bauza A, Grases F. Evidence of Higher Oxidative Status in depression and Anxiety. Oxidative Medicine and Cellular Longevity. 2014;430216. https://doi.org/10.1155/2014/430216.

10. Scapagnini G, Davinelli S, Drago E, de Lorenzo A, Oriani G. Antioxidants as antidepressants: fact or fiction? CNS Drugs. 2012;26(6):477-90. https://doi. org/10.2165/11633190-000000000-00000.

11. Suga H, Asakura K, Kobayashi S, Nojima M, Sasaki S. Three-generation Study of Women on Diets and Health Study Group. Association between habitual tryptophan intake and depressive symptoms in young and middle-aged women. J Affect Disord. 2018;231:44-50. https://doi.org/10.1016/.j.jad.2018.01.029.

12. Urrilla AS, Hakkarainen A, Castaneda A, Paunio T, Marttunen M, Lundbom N. Frontal cortex Myo-inositol is associated with sleep and depression in adolescents: a proton magnetic resonance spectroscopy study. Neuropsychobiology. 2017;75(1):21-31. https://doi.org/10.1159/000478861.

13. Schlemmer U, Frolich W, Prieto RM, Grases F. Phytate in foods and significance for humans: food sources, intake, processing, bioavailability, protective role and analysis. Mol Nutr Food Res. 2009;53(Suppl 2):S330-75. https://doi.org/10.1002/mnfr.200900099.

14. Ganchevas S, Galunska B, Zhelyazkova-Savova M. Diets rich in saturated fat and fructose induce anxiety and depresión-like behaviours in the rat: is there a role for lípido peroxidation? Int J Exp Pathol. 2017;98(5):296-306. https://doi.org/10.1111/iep.12254

15. Sanchez-Villegas A, Zazpe I, Santiago S, Perez-Comago A, Martinez-Gonzalez MA, Lahortiga-Ramos F. Added sugars and sugar-sweetened beverage consumption, dietary carbohydrate index and depression risk in the 
Seguimiento Universidad de Navarra (SUN) project. Br J Nutr. 2018;119(2): 211-21. https://doi.org/10.1017/S0007114517003361.

16. Knuppel A, Shipley MJ, Llewellyn CH, Brunner EJ. Sugar intake from sweet food and beverages, common mental disorder and depresión: prospective findings from the Whitehall II study. Sci Rep. 2017;7(1):6287. https://doi.org/ 10.1038/s41598-017-05649-7.

17. Adjibade M, Assmann KE, Andreeva VA, Lemonge C, Hercberg S, Galan P, KesseGuyot E. Prospective association between adherence to the Mediterranean diet and risk of depressive symptoms in the French SU. VI.MAX cohort. Eur J Nutr. 2018;57(3):1225-35. https://doi.org/10.1007/s00394-017-1405-3.+.

18. Willett WC, Sacks F, Trichopoulou A, Drescher G, Ferro-Luzzi A, Helsing E, Trichopoulos D. Mediterranean diet pyramid: a cultural model for healthy eating. Am J Clin Nutr. 1995;61(6):1402S-6S. https://doi.org/10.1093/ajcn/61.61402S.

19. Beck AT, Rush A J, Shaw B E, Emery G. Beck Depression Inventory. Cognitive Therapy of Depression, Guilford press, New York, NY, Usa, 1979, trad Esp en Bilbao: Desclee de Brouwer, 1983.

20. Bishwajit G, O'Leary DP, Ghosh S, Sanni Y, Shangfeng T, Zhanchun F. Association between depression and fruit and vegetable consumption among adults in South Asia. BMC Psychiatry. 2017;17:15. https://doi.org/10 1186/s12888-017-1198-1.

21. Paskulin JTA, Drehmer M, Olinto MT, Hoffman JF, Pinheiro AP, Schmidt MI, Nunes MA. Association between dietary patterns and mental disorders in pregnant women in Southern Brazil. Rev Bras Psiquiatr. 2017;39(3):201-15. https://doi.org/10.1590/1516-4446-2016-2016.

22. Wolniczak I, Caceres-DelAguila JA, Maquiña JL, Bernabe-Ortiz A. Fruits and vegetables consumption and depressive symptoms: A population-based study in Peru. Plos One. 2017;12(10):e0186379. https://doi.org/10.1371/ journal.pone.0186379.

23. Maes M, Mihaylova M, Kubera M, Uytterhoeven M, Vrydags N, Bosmans E. Increased plasma peroxides and serum oxidized low density lipoproteín antibodies in major depression: markers that further explain the higher incidente of neurodegeneration and coronary artery disease. J Affect Disord. 2010;125(1-3):287-94. https://doi.org/10.1016/j.jad.2009.12.014.

24. Maes M, Mihaylova I, Kubera M, Uytterhoeven M, Vrydags N, Bosmans E. Increased 8-hydroxy-deoxyguanosine, a marker of oxidative damage to DNA, in major depression and myalgic encephalomyelitis/ chronic fatigue syndrome. Neuroendocrinol Lett. 2009;30(6):715-22.

Ready to submit your research? Choose BMC and benefit from:

- fast, convenient online submission

- thorough peer review by experienced researchers in your field

- rapid publication on acceptance

- support for research data, including large and complex data types

- gold Open Access which fosters wider collaboration and increased citations

- maximum visibility for your research: over $100 \mathrm{M}$ website views per year

At $\mathrm{BMC}$, research is always in progress.

Learn more biomedcentral.com/submissions 